\title{
Hungry Cat-A Serious Game for Conveying Spatial Information to the Visually Impaired
}

\author{
Carmen Chai ${ }^{1, *}$, Bee Theng Lau ${ }^{1}$ and Zheng Pan ${ }^{2}$ \\ 1 Faculty of Engineering, Computing and Science, Swinburne University of Technology Sarawak Campus, \\ 93350 Kuching, Sarawak, Malaysia; blau@swinburne.edu.my \\ 2 Department of Accounting and Information Systems, University of Canterbury, Christchurch 8041, \\ New Zealand; panzheng@ieee.org \\ * Correspondence: cchai@swinburne.edu.my
}

Received: 8 January 2019; Accepted: 22 February 2019; Published: 27 February 2019

\begin{abstract}
Navigation is done through obtaining spatial information from the environment and forming a spatial map about it. The visually impaired rely mainly on orientation and mobility training by a certified specialist to acquire spatial navigation skills. However, it is manpower intensive and costly. This research designed and developed a serious game, Hungry Cat. This game can convey spatial information of virtual rooms to children with visual impairment through game playing. An evaluation with 30 visually impaired participants was conducted by allowing them to explore each virtual room in Hungry Cat. After exploration, the food finding test, which is a game mode available in Hungry Cat, was conducted, followed by the physical wire net test to evaluate their ability in forming the spatial mental maps of the virtual rooms. The positive results of the evaluation obtained demonstrate the ability of Hungry Cat, in conveying spatial information about virtual rooms and aiding the development of spatial mental maps of these rooms through game playing.
\end{abstract}

Keywords: serious game; spatial information; spatial navigation; spatial mental map; visual impairment; special needs; children

\section{Introduction}

It is without a doubt that spatial information plays an important role in day to day life. It is used to plan how to navigate from one place to another, for maneuvering in a complicated environment such as a crowded shopping mall, and even for recalling where one's car is parked and returning to it. As one navigates through an environment, information about the environment is obtained from multiple sources. The information obtained includes general knowledge about the place, written or verbal descriptions of the environment, visual experience, personal experiences of being in the environment and others. All of these come together to create a spatial mental map of that place in the person's mind [1].

Navigation can be done in two distinct methods. First is the landmark-based navigation, which employs the information provided by environmental landmarks in the form of vision, audio, smell and tactile stimuli along with an internal cognitive map of the place to navigate. The second method is the path integration method, which is the common and preferred method of visually impaired individuals. This navigation method relies on the traveler's sense of motion to update their position and orientation in relation to their starting point [2].

Besides gathering spatial information about an area through navigating it first hand, prior knowledge such as the spatial layout of the area and knowing your current location in the area is also important. Hence, visiting virtual reality simulations of real locations as well as fictitious ones in order to gain spatial information has been suggested [3]. A study that developed a virtual environment 
Wii-based system for the blind has found that virtual environments can help with the gaining of spatial knowledge [4].

Although visual experience plays a vital role in the creation of a spatial mental map, blind individuals can gather spatial information without it. They compensate for their lack of vision with their enhanced hearing, touch and sense of smell to obtain information about a specific place. This information includes environmental sounds, sense of heat to detect the weather or sunshine, feeling of wind movement, and even the slope and texture of the ground surface [5].

Additionally, a study has found that blind individuals have a preference for route-like descriptions while sighted individuals performed better with survey-like descriptions of an environment. This shows that early blind or naturally blind individuals produce route-like spatial mental model to represent an environment, in contrast to the survey-like or map-like representation of sighted individuals [6].

This article aims to convey the development and evaluation of a mobile serious game, named Hungry Cat, created for visually impaired children in helping them to gather spatial information through playing a game.

\section{Related Work}

This section covers existing spatial information conveying tools, serious games for conveying spatial information as well as discussed the limitations of these existing tools.

\subsection{Spatial Information Conveying Tools}

Several studies have investigated tools to aid the visually impaired in obtaining spatial information about a place. Among these tools, there are some that do not involve a virtual reality environment, for example the audio and haptic feedback based environment map representation, Omero [7]; audio-based metro route simulator, Audio Metro [8]; the tactile raised-line maps inspired virtual map exploration via smartwatch [9]; and a camera-based constructive exploration system and force feedback-based constructive exploration system [10]. These applications do not let the user explore the environment in a first-person point of view.

Related studies that involved virtual reality software to provide spatial information to the visually impaired include the Audio Haptic Maze (AHM) [11], the BlindAid [12,13], an auditory-based architectural exploration tool for corridors [14], a training tool for the newly blind [15], a traffic crossing simulator [16], an audio haptic-based exploration of virtual maps using a tactile mouse device [17], an audio haptic-based simulator using haptic device [18], VirtualLeap and VirtualWalk app [19], and a multi-sensory (audio and haptic) virtual environment [20]. Some of these examples use multimodal interfaces, utilizing both audio and haptic feedback $[11-13,17,18,20]$. These were shown to be useful to the visually impaired in creating a better perception of their virtual environment. These applications allow the user to experience the environment in the first-person point of view, which helps emulate the path integration navigation method stated previously.

A comparison has been done between real world training and virtual environment training with blind individuals. The study has shown that longer exposure of $5 \mathrm{~min}$ to training in a virtual environment could surpass real world training when compared to the shorter exposure to training in a virtual environment of $2 \min [21]$.

\subsection{Serious Games for Conveying Spatial Information}

Serious games, also known as applied games, have been created for education by providing a platform for making boring tasks a bit more engaging by presenting these tasks as a game. Such games have been created for activities such as practice, training and providing solutions and are used in various fields such defense, healthcare, research, production, and learning about cultural heritage [22]. An example of a serious game is the Virtual Factory [23]. It was created to provide the players with more information about the Industrial Engineering (IE) field within a manufacturing environment. 
Results show that the pre-college and freshman student participants had become more motivated to pursue the IE field after playing the game. The game also increased their understanding on how IE is used in a manufacturing environment.

Serious games have been developed to aid children as well, such as for children with attention deficit hyperactivity disorder [24] and for children with speech disorders and hearing problems [25]. These kinds of games allow children to learn independently and, being games, may motivate more participation from the children. The teacher, therapist or specialist will not have to be there to guide the children as in normal teaching sessions, thus saving time and manpower. Serious games can also allow progress of students to be assessed after they have played with the games.

Audio-based Environment Simulator $(\mathrm{AbES})$ was developed to determine if a virtual environment simulator can enhance the wayfinding abilities in blind individuals [26]. AbES allows the user to virtually explore an actual physical location, in this case a real building layout using the context of a game. The serious video game was developed to help the blind player acquire a detailed and reliable spatial cognitive map of the building according to the different game level.

The effectiveness of the gameplay element of the software was tested by conducting navigational tasks with two groups of blind participants [27]. The tests concluded that the "gamer" group showed that the free exploration of the game environment provided them with a better and more flexible mental spatial map of the spatial information obtained via the gameplay.

The AbES video game was also tested with a sample of blind adolescences. It was able to transfer spatial information to these younger participants, which allowed them to successfully navigate a real-world building that was represented within the game [28].

\subsection{Limitations of Existing Spatial Information Conveying Tools}

Although the number of tools described in the related studies discussed above were effective at conveying spatial information, there were several drawbacks. Firstly, they were not built with the children in mind [7-10,12,14-20,26], therefore they included complex environments and controls that may be difficult to grasp and can be daunting for younger users. By requiring high levels of cognition and attention spans, the existing spatial information conveying tools do not seem suitable for visually impaired children.

These systems were mostly developed for use on a desktop computer and many of them require extra equipment to be set up $[11-13,15,17,18,20]$, such as the use of orientation and mobility sensors as well as haptic devices. This results in a lack of portability. Reproducing these setups would be difficult, making them infeasible for general use. The lack of portability means that the tools can only be used at the location it is set up.

Most of these tools are also not in the form of games, which may be dull and less attractive for children [7-10,12-20]. The formal tone and the lack of interesting elements may bore the children, resulting in a lack of motivation to participate and explore the virtual environment.

In summary, there should be a tool to provide spatial information that is designed for visually impaired children. This tool should be easy for children to learn to use and come in the form of a game.

\section{A Serious Game, Hungry Cat}

This research aimed to design, develop and evaluate an audio and haptic feedback based serious game prototype for children with visual impairment which is easy to setup and use. A serious game, namely Hungry Cat was proposed as a learning tool to convey spatial information to visually impaired children through the exploration of virtual rooms.

Hungry Cat, which was developed using Unity 5, is a 2D serious game running in Android mobile platform. The mobile platform, specifically Android, was chosen because playing the game only requires the use of the device as well as a set of headphones. This also utilizes the mobile sensors within the devices for a more intuitive game play. 
In this game, the children gain spatial information about a virtual environment by controlling an avatar, i.e., the Hungry Cat. Set in the perspective of the cat avatar looking for food, Hungry Cat allows players to move through the virtual rooms in a house using simple controls and physical movement. These controls are detected by the game using the mobile sensors: accelerometer and magnetometer.

The game environment is made up of a two-dimensional area consisting of tiles, where players can choose to move forward, backward, left or right within it to discover the objects in the room. Objects and obstacles are identified when bumping into or interacting with by the player or can be discovered through the audio and haptic feedback the environment provides. There is also a food object available for the food finding mode gameplay. Sounds can be heard when a player gets closer to them to provide an audio landmark to the player.

The time taken for the player to complete the levels and actions taken such as number of steps, number of turns and number of interactions with the environment are recorded and saved as a text file for later analysis. Figure 1 summarizes the conceptual architecture.

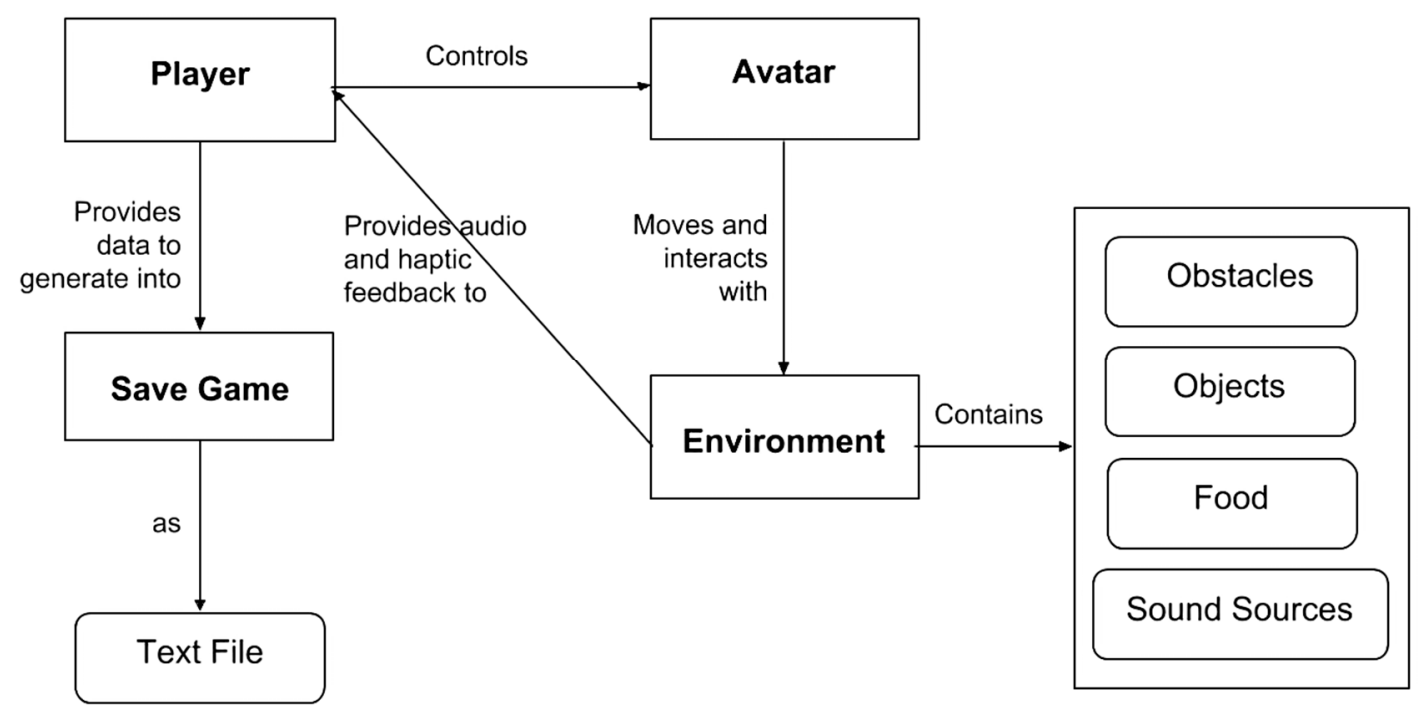

Figure 1. Conceptual architecture of Hungry Cat.

\subsection{Layout of Levels}

It should be noted that this game is not fully blind friendly and navigation between interfaces will require sight. The user interfaces seen are mainly for easier game development and also for ease of use for the sighted test facilitator. The only blind friendly interface in this game is of the gameplay itself, which does not require sight to interact with.

A general room layout in Hungry Cat is shown in Figure 2. It depicts the user interface, UI elements and game environment features that are available in all rooms, with the exception of the Food object and the Interactive object. 


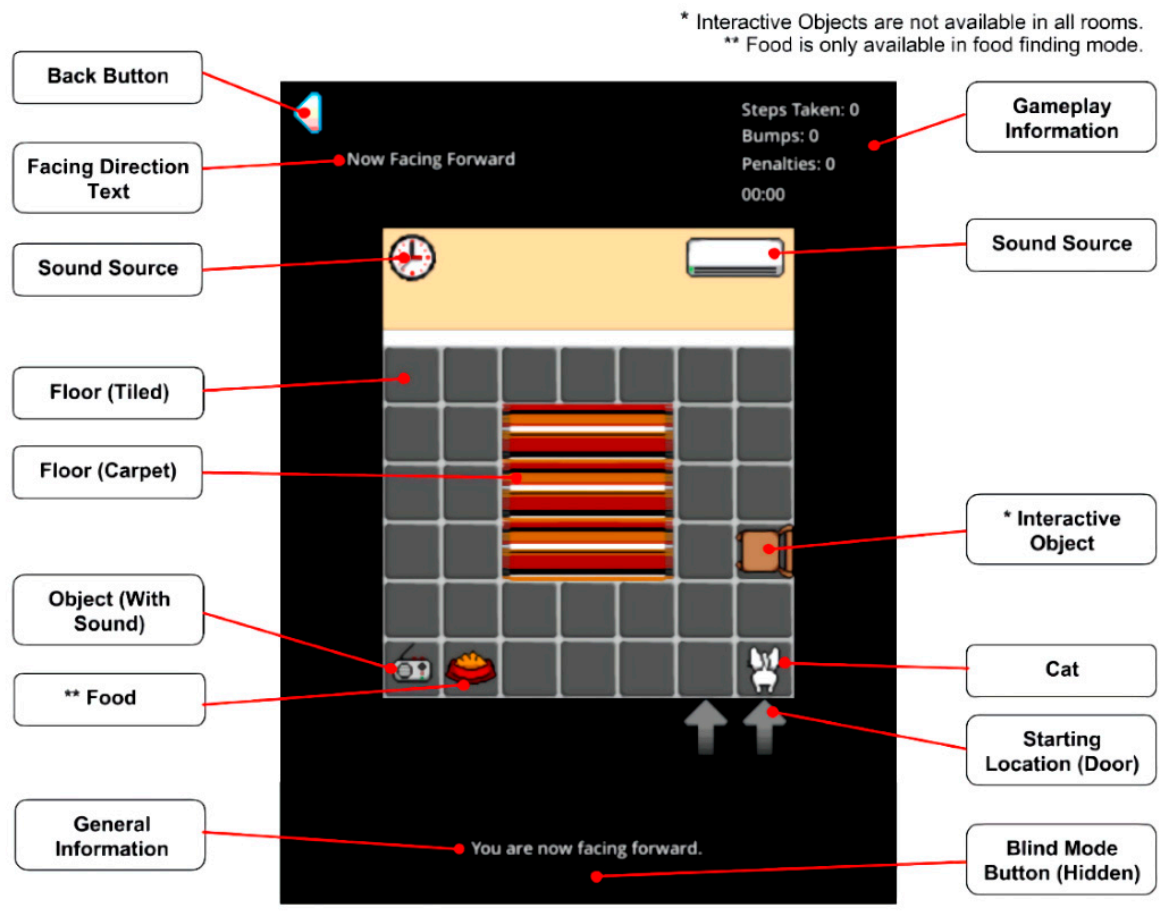

Figure 2. General layout for one of the rooms.

As shown in Figure 2, there are several user interface elements. The Back Button is for going back to the main menu. This is for exiting the level easily. The Blind Mode Button, which is hidden from view, is used to toggle on and off between the blind mode. The Blind Mode is on by default to prevent the advantage of using residual vision to view the map, by covering the map of the room up, as shown in Figure 3. The button for toggling the blind mode is to enable the facilitator of the test to quickly determine how the participant is doing if assistance is required during game play.

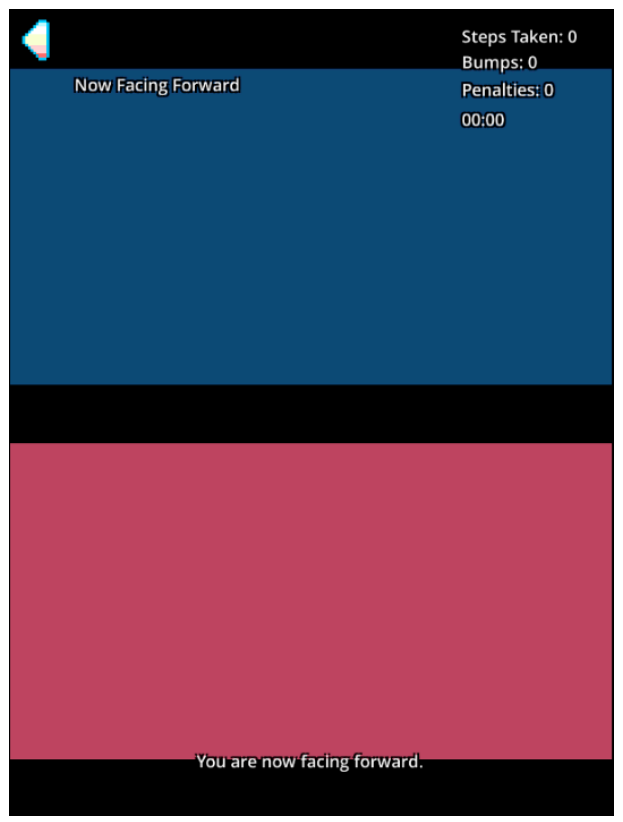

Figure 3. Screenshot of game level with blind mode on. 
Other UI elements are for information purposes, that is to inform about the facing direction of the participant, and general information such as what objects they have bumped into and game play information such as the time left, steps taken, bumps made and penalties that occurred.

All room levels are surrounded by a black background, representing the walls. The player is not able to leave the area bordered by the walls. In the case where the player bumps against the walls and doors, a combination of auditory and haptic/vibrational feedback is produced by the game. The doorway is represented by the two arrows pointing upwards and is the start location of the player when the game level begins. The player always begins the game on the right-hand tile of the doorway.

All rooms have floor tiles that can come in a few variations. Some rooms may have tiled floors, some rooms may have wooden floors, and some rooms may contain carpets. Different variations of floors provide different auditory and haptic feedback when the Cat steps on them.

Each room has at least one sound source to help players orient themselves. These are normally against the walls of the room and are not objects that can be bumped into. There are additionally objects that give off sounds such as the radio in Figure 2. However, not all objects have a sound effect attached to it such as for cabinets and potted plants.

More difficult levels contain rooms with more interactive objects which are climbable to reach a higher location. This is because food items located in the harder levels are usually placed on an elevated surface and requires an amount of knowledge of the room to be able to locate it. With this placement, it is impossible for the food to be found simply by walking around the room. While on an elevated surface, the player has to perform a tile check to trigger an action to climb down. Trying to walk off a high surface results in a penalty in the game.

\subsection{Intuitive Controls}

Controls in the game are designed to be simple and intuitive so that even young children can play the game. By utilizing the mobile sensors within the mobile device such as the accelerometer and magnetometer, complicated setups and special equipment such as heading sensors are not required. The game can be played while being seated on a swivel chair or a stool without backing, or while standing on the spot with just the device and a pair of stereo headphones. This will allow the game to be played at any place at any time.

To move forward within the virtual room in the game, the player simply has to tilt the device forward. The accelerometer sensor detects this movement and allows the cat to move forward at one step per second. To stop moving forward, the player only needs to stop tilting the device forward. If the player keeps moving forward even though there is an item or obstacle in front of them, the game lets them know that they have bumped into something. This method of letting the player move the cat will allow the player to navigate around the virtual room without moving around physically themselves.

To change the cat's facing direction, the player needs to change their real facing direction while holding the device. The magnetometer within the device detects the change in facing direction and updates the cat's facing direction accordingly, be it forward, left, backward or right. With these two controls, the player can move around in the environment and discover the furniture and obstacles that are present in the room.

Besides movement controls, there are other controls that allow the player to gather more information about the environment. The first control is accessed by tapping the top half of the screen. This provides the player with information of the tile that they are facing. For example, if they are facing a wall, the game tells them "You are facing a wall." This is the alternate way of knowing what the item in front of the player is without bumping into it. The second control is accessed by tapping the bottom half of the screen. This provides the player with their current location information such as what tile they are standing on. If they are playing the game on food finding mode, it repeats the directions to food and informs the player how far away from the food. The information can be long so the player can cancel the speech at any time by tapping the top half of the screen. 
In some stages, there are interactions with furniture. This allows the cat to climb onto or down from an elevated area to look for food. If a furniture has interactions available, one can access the option by tapping the top half of the screen when facing the furniture. This provides the player with action options to choose from. They can select an action by tapping either the top half of the screen or bottom half of the screen depending on their choice.

\subsection{Progressive Stages and Modes}

To counter the issue of overcomplicated environments for a game intended for children, this game has a tutorial room and six playable rooms with increasing difficulties. The difficulty increases as the rooms get larger and have more furniture in them. The presence of interactive items that allow climbing also increases the difficulty level of the game. The six rooms in the order of ascending difficulty levels are the hallway, laundry room, study room, bedroom, kitchen and living room.

All these stages can be played in two different modes. The first mode is the exploration mode, which gives the player $5 \mathrm{~min}$ to freely explore the selected room level. The second mode is the food finding mode, which is the same room that the player had just explored except that the room has a food item in it. Figure $4 \mathrm{a}, \mathrm{b}$ shows screenshots of the bedroom level for both game play modes.

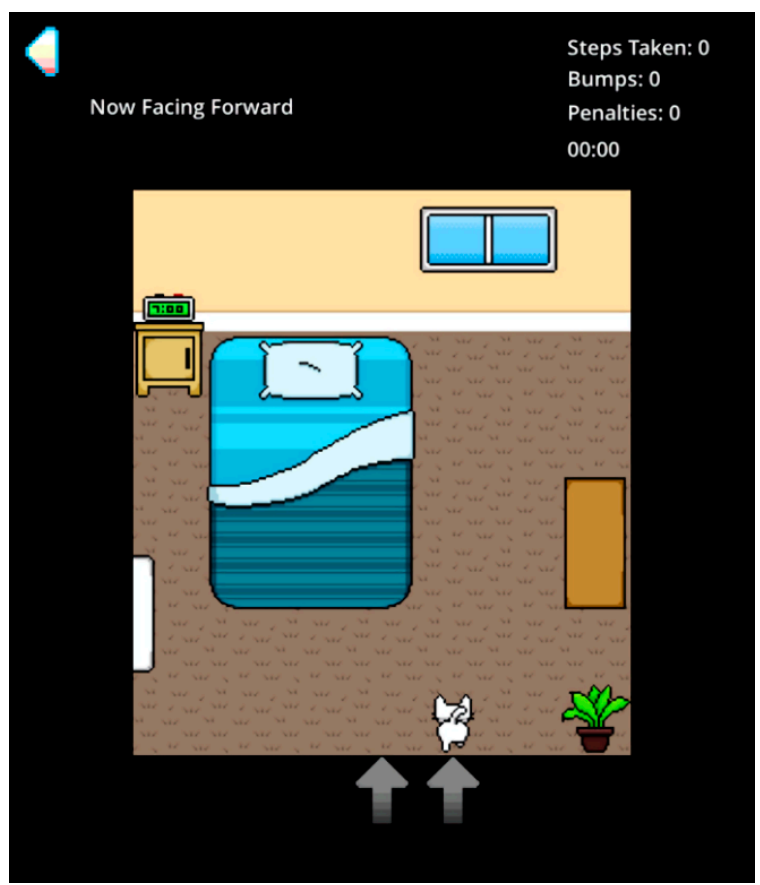

(a)

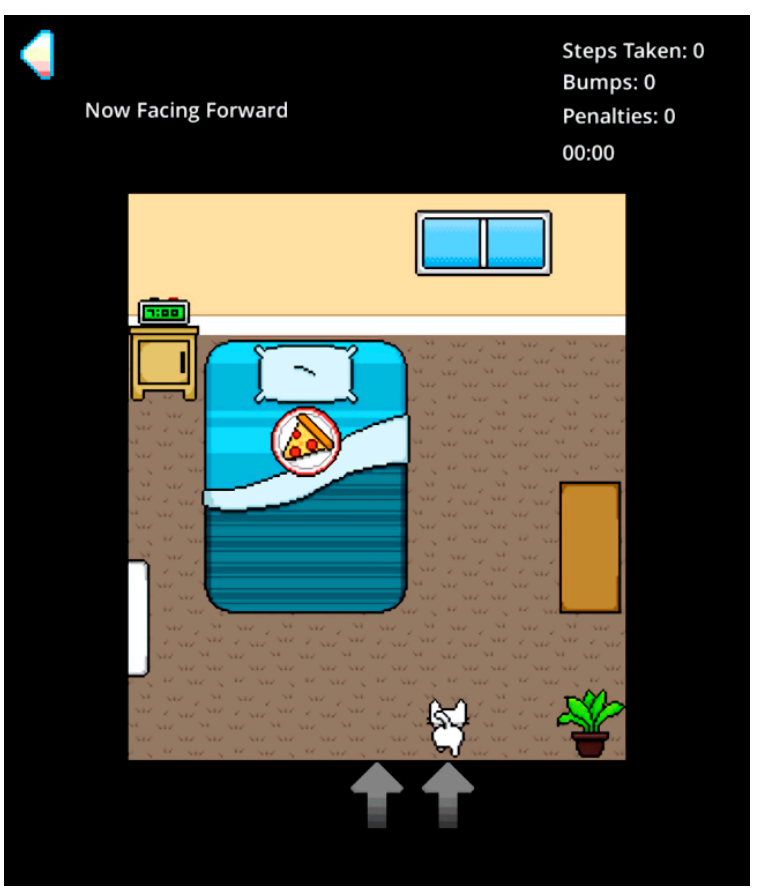

(b)

Figure 4. Hungry Cat, bedroom level: (a) in exploration mode; and (b) in food finding mode.

\subsection{Real Time Audio and Haptic Cues}

The game utilizes audio cues in the form of pre-generated speech and sound effects, as well as haptic cues which is the vibration feedback from the device, to provide clues of the game environment.

The game provides speech descriptions whenever players seek a clue such as when they want to check the item in front of them and ask for location information. The speech in the game is available in two languages: English and Bahasa Melayu, to assist the Bahasa Melayu speaking participants.

Audio cues may come from furniture within the rooms such as a dripping sink or a radio. The sounds from these items are in stereo, meaning that it becomes louder if the player is facing it and softer if the player is facing away. If the furniture is on the player's left, they will hear it louder in the left ear than the right ear. The sounds get louder if the players get nearer to it and softer when they are 
further away. Similarly, the food item plays a song, which acts as a clue to the players about how close they are to it. This to emulate the presence of the smell of food in reality.

The haptic feedback in the game happens when players take steps forward. This allows the players to count their steps. Vibration feedback also occurs when players bump into an item or obstacle. The intensity of the vibration is affected by how hard the surface is, for example stepping on a carpet has lighter vibrations than stepping on a tiled floor.

All these aid the development of a player's spatial mental mapping of the virtual rooms via an immersive experience during the exploration of the rooms.

\subsection{Performance Monitoring}

For the purpose of analysis, the game tracks the number of times the player takes a particular action while playing the game. Before playing the game, the player's name can be registered and selected. This produces a record containing the individual game play data such as when time is up, when food is found or when the player chooses to stop playing before the time is up. Information such as time taken, steps taken, number of bumps into furniture, turns made, etc. are being counted and recorded during game play. This is used to monitor the progress of the player to see if they have become more efficient at navigating the room and finding the food.

\section{Evaluation of Hungry Cat}

The game was evaluated in two phases with 30 participants (aged 7-17 years) who are visually impaired. Phase 1 was the food item finding test using Hungry Cat game in a tablet computer while Phase 2 was the wire net item test. There was an exploration mode session prior to running Phase 1 test where the participants explored each virtual room in Hungry Cat game using a tablet computer. Upon completing the exploration mode session, participants went into Phase 1 followed by Phase 2 . The evaluations aimed to determine the success of Hungry Cat in conveying spatial information to participants. The spatial mental maps of the rooms formed by participants in Phase 2 could demonstrate the spatial information they obtain successfully through playing the Hungry Cat game.

It should be noted that the evaluation of this game was as a tool to convey spatial information to visually impaired children and was not a form of intervention to improve the participants' spatial navigation abilities. Therefore, there was no control group for result comparison or any pre and post intervention tests.

\subsection{Participants}

To determine if the game developed can convey spatial information to visually impaired children, tests were conducted with 30 visually impaired children aged 7-17. The participants of this study consisted of multiple groups: primary and secondary school students, low vision and with no vision, as well as students with learning difficulties and students who do not. Table 1 shows the participant overview of this study.

To take part in this study, some selection criteria needed to be met: age between 7 and 17 years old, visually impaired (having low vision or no vision), and ability to understand and follow simple instructions in English or Bahasa Melayu. All participating subjects as well as their parent/guardian were informed of the course and purpose of the experiment. The parent/guardian of each participant signed an informed consent documentation before participation. 
Table 1. Participant overview.

\begin{tabular}{|c|c|c|c|}
\hline Age Group & No. & No Vision/Low Vision & Learning Difficulty \\
\hline \multirow{9}{*}{ Primary School } & 1 & Low Vision & $\checkmark$ \\
\hline & 2 & Low Vision & \\
\hline & 3 & Low Vision & \\
\hline & 4 & No Vision & \\
\hline & 5 & No Vision & \\
\hline & 6 & Low Vision & \\
\hline & 7 & No Vision & $\checkmark$ \\
\hline & 8 & Low Vision & \\
\hline & 9 & Low Vision & $\checkmark$ \\
\hline \multirow{21}{*}{ Secondary School } & 10 & Low Vision & \\
\hline & 11 & Low Vision & \\
\hline & 12 & Low Vision & \\
\hline & 13 & Low Vision & \\
\hline & 14 & No Vision & \\
\hline & 15 & Low Vision & \\
\hline & 16 & Low Vision & \\
\hline & 17 & Low Vision & \\
\hline & 18 & No Vision & \\
\hline & 19 & No Vision & \\
\hline & 20 & No Vision & $\checkmark$ \\
\hline & 21 & Low Vision & \\
\hline & 22 & No Vision & \\
\hline & 23 & No Vision & $\checkmark$ \\
\hline & 24 & No Vision & \\
\hline & 25 & No Vision & $\checkmark$ \\
\hline & 26 & No Vision & \\
\hline & 27 & Low Vision & \\
\hline & 28 & Low Vision & \\
\hline & 29 & No Vision & $\checkmark$ \\
\hline & 30 & Low Vision & \\
\hline
\end{tabular}

\subsection{Ethics Clearance}

All subjects gave their informed consent for inclusion before they participated in the study. The study was conducted in accordance with the Declaration of Helsinki, and the protocol was approved by the Swinburne Human Research Ethics Committee (SHR Project 2016/316).

\subsection{Pre-Test Setup}

Prior to beginning the tests, the tablet device was setup with the participants' names and preferred language. The stereo headphone volumes and the height of their seat, a swivel chair, was then adjusted so that the participant feel comfortable while playing the game. The wire net test form was filled with the participant's name at this time as well. After all these were done, the participant started playing the exploration mode for the room chosen. Participants were given a time limit of 5 min to explore each room. All tests were conducted in an unused classroom after class hours, during which there were minimal distractions if any from other students. As the participants used stereo headphones, any external noise would have been muted and they were able to concentrate more on the game.

\subsection{Phase 1: Food Item Finding Test}

The first test was the food finding test. This test was carried out after the participant was finished exploring the room. The food finding mode of the same room was played and the directions to the food are given before the level begins. The participant was given $5 \mathrm{~min}$ to locate the food within the room. If they managed to find the food within the 5-min limit, they passed the food finding test. If the time ran out before they managed to do so, they failed. Participants who failed this test were not 
allowed to replay the level. The gameplay variables for both the exploration mode and food finding mode play through of the participant was recorded by the game and exported to a text file for analysis.

The objective of the food finding test was to see if the participants could locate the food placed in the room using the spatial mental map they constructed of that room during exploration mode. The food finding test tested how well Hungry Cat conveys spatial information, as having a good spatial mental map of the room can help the participant to perform well. With the spatial information obtained from the exploration of the room prior to this test, the participant should be able to locate the food quickly after being provided with the directions to the food. Knowledge of the placement of items in the room would allow the participant to quickly and efficiently locate the food objective regardless of whether the furniture items were in the path from the starting point to the food. They would be able to use the spatial mental map of the room to plan a route with the fewest obstacles. However, participants might also be able to reach the food without a spatial mental map.

\subsection{Phase 2: Wire Net Test}

The second test was the wire net test. This test was carried out after the food finding test was completed, regardless of whether the participant had managed to find the food. It was a non-visual test that allowed blind participants to point out the location and size of objects in the room. It was done using a wire net with holes that represent the individual tiles in the room, and a mounting board frame representing the borders of the room's walls, as shown in Figure 5a,b. A bottle cap was used to indicate the starting position of the cat in the room. By using a wire net with mounting board, the blind participants were able to feel the borders of the room as well as the individual tiles and were able to point out the location as well as size of the furniture items they have discovered in the room. Some prompting was sometimes required to help the participant show their spatial mental map as fully as possible such as "What else have you discovered?" and "What is the size of this furniture?".

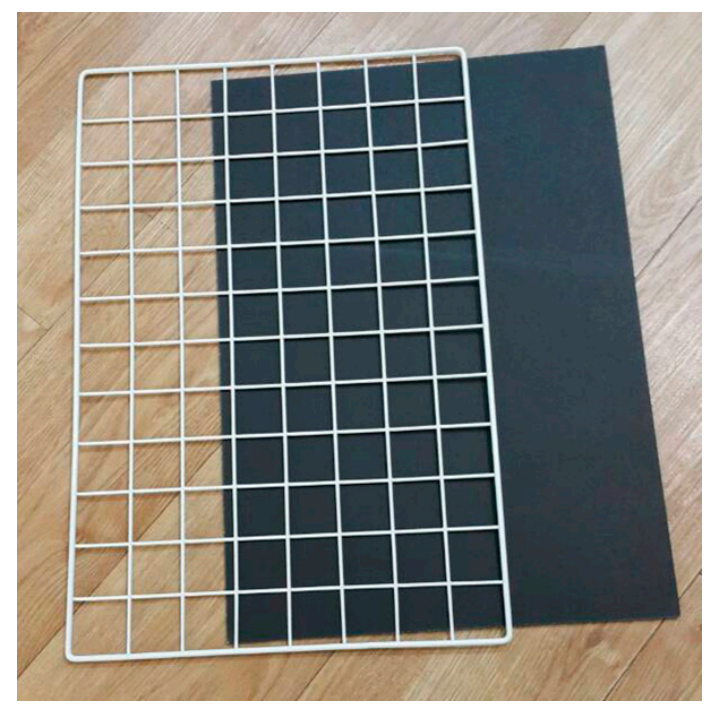

(a)

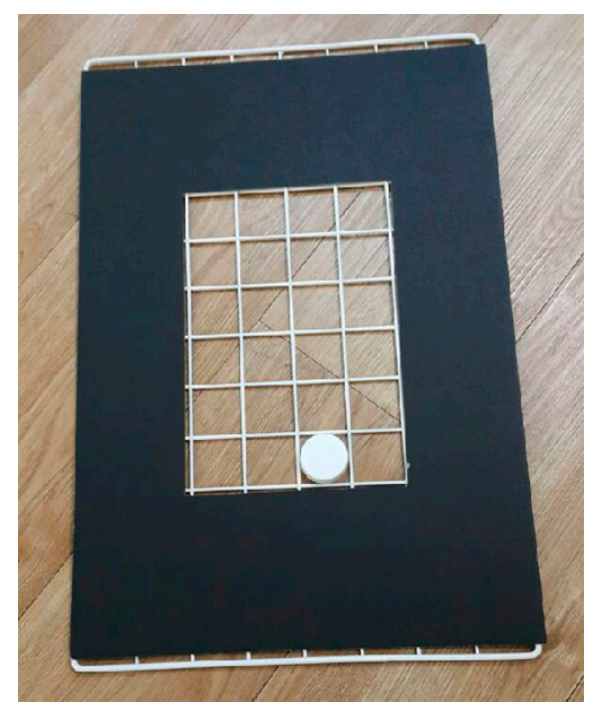

(b)

Figure 5. Photos of wire net and mounting board: (a) wire net and pre-cut mounting board; and (b) wire net with mounting board frame for laundry room game level.

The location and size of the items pointed out by the participant were noted on their wire net test form. The empty wire net test form is shown in Figure 6a, while a scan of a filled in form from the evaluation is shown in Figure 6b. The item's accuracy score was then calculated based on whether the participant had discovered the item, how accurately it was placed and how accurately the size was described. The wire net test was designed so that the participants did need not navigate around a real 
environment to prove their understanding of the layout of the room they had explored. This test was conducted in a safe manner.

The objective of the wire net test was to allow participants to explain their spatial mental map of the room in detail. The wire net test tested how well Hungry Cat can convey spatial information, as the participants needed to point out which furniture they discovered as well as place them on the wire net test frame of the room. The size and location of these furniture needed to be given by the participant during the test and this allowed the participants to demonstrate if they have a solid mental map of the room.

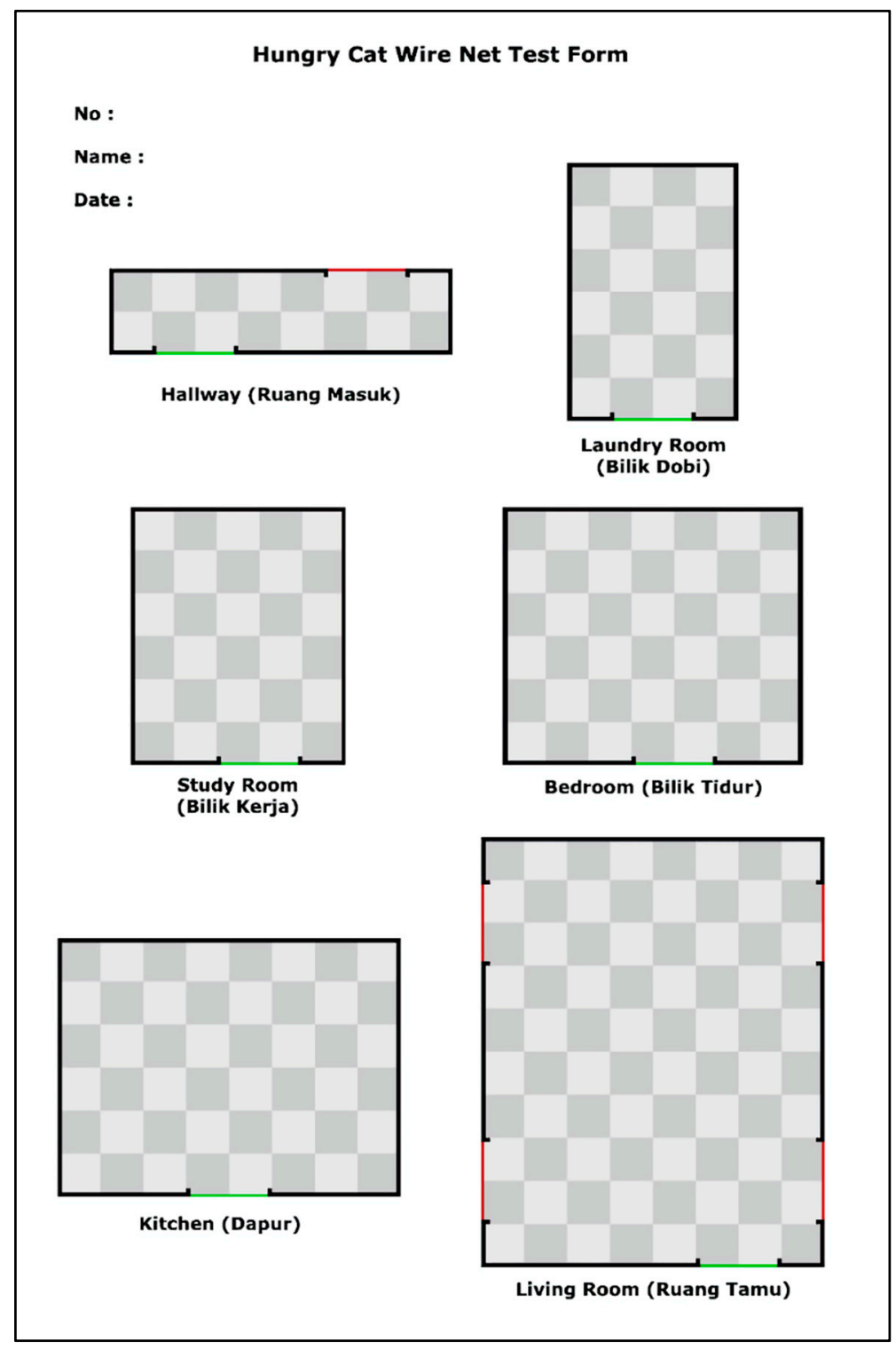

(a)

Figure 6. Cont. 


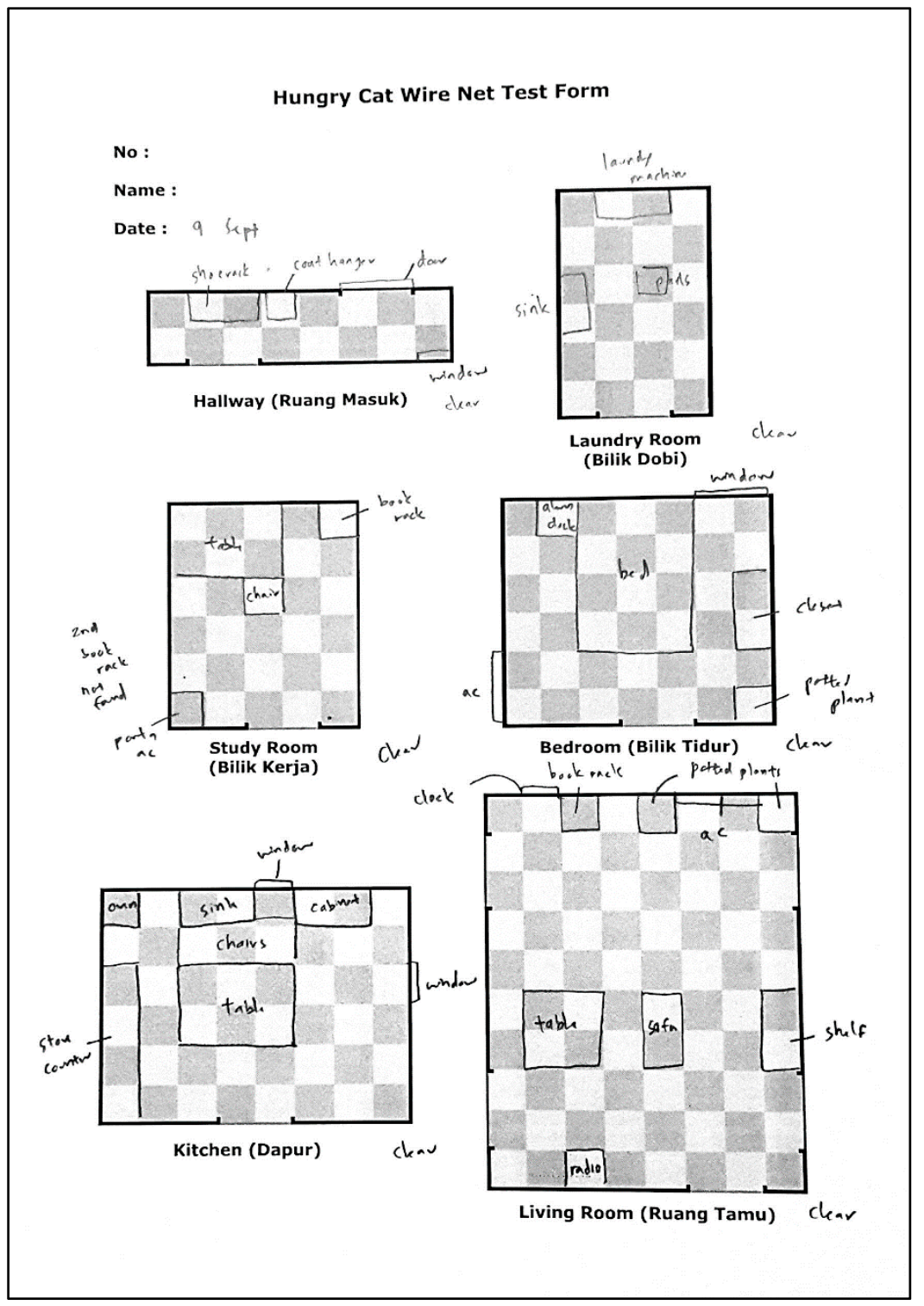

(b)

Figure 6. Wire net test result recording form: (a) empty form; and (b) scan of filled in form sample from evaluation (name censored for privacy).

\section{Results and Findings}

This section shows the results of both the food finding tests and the wire net tests conducted with the 30 participants. It is followed by a discussion of the results and the contributions of the study to its research objectives.

\subsection{Food Finding Tests Results}

The food finding test results were compared among several categories: primary school participants and secondary school participants, participants with no vision and participants with low vision and participants with learning difficulties (LD) and participants without learning difficulties. Out of the 30 participants, 9 were in primary school while 21 were in secondary school. There were 13 with no vision while 17 had low vision. Seven had learning difficulties while 23 had no learning difficulties. The success rate of each group of participants is shown in Table 2. 
Table 2. Success Rate (\%) of Food Finding Test in Various Groups.

\begin{tabular}{|c|c|c|c|c|c|c|c|c|}
\hline Group & $\begin{array}{l}\text { Number of } \\
\text { Participants }\end{array}$ & Hallway & $\begin{array}{l}\text { Laundry } \\
\text { Room }\end{array}$ & $\begin{array}{l}\text { Study } \\
\text { Room }\end{array}$ & Bedroom & Kitchen & $\begin{array}{l}\text { Living } \\
\text { Room }\end{array}$ & Average \\
\hline Primary School & 9 & 55.56 & 44.44 & 11.11 & 55.56 & 11.11 & 0.00 & 29.63 \\
\hline No Vision & 13 & 61.54 & 53.85 & 0.00 & 30.77 & 0.00 & 7.69 & 25.64 \\
\hline Low Vision & 17 & 64.71 & 52.94 & 11.76 & 58.82 & 17.65 & 11.76 & 36.27 \\
\hline With LD & 7 & 42.86 & 57.14 & 0.00 & 42.86 & 0.00 & 14.29 & 26.19 \\
\hline
\end{tabular}

The success rate of food finding among secondary school participants (32.54\%) were generally higher on average than those of primary school participants $(29.63 \%)$. The success rate of food finding by participants with low vision $(36.27 \%)$ were generally higher than those with no vision $(25.64 \%)$. Lastly, the success rate of food finding by participants with no learning difficulties (33.34\%) were generally higher than those with learning difficulties (26.19\%). However, the study could not fully verify this, as there was a limited number of participants with learning difficulties.

Participants who found the food in the food finding mode, and passed the food finding test, had actually interacted with the game more during the exploration mode. These participants took more steps and performed more checks for information about the tile in front of them, as can be seen in Figures 7 and 8 . By taking more steps while exploring the room, the participant discovered more sections of the virtual room, and, by performing more tile checks, the participant gained more information about the tiles within the virtual room. Both these actions were useful for gathering spatial information, which was significant for constructing a proper spatial mental map of the virtual room.

However, Figure 9 does not show that participants who passed the food finding test performed more information checks in every room. This demonstrates that the information check was not required for the participant to gather sufficient data about the room.

The information check in exploration mode only provides information on the current location, which is the tile the player is standing on, for example, "You are standing on top of a chair".

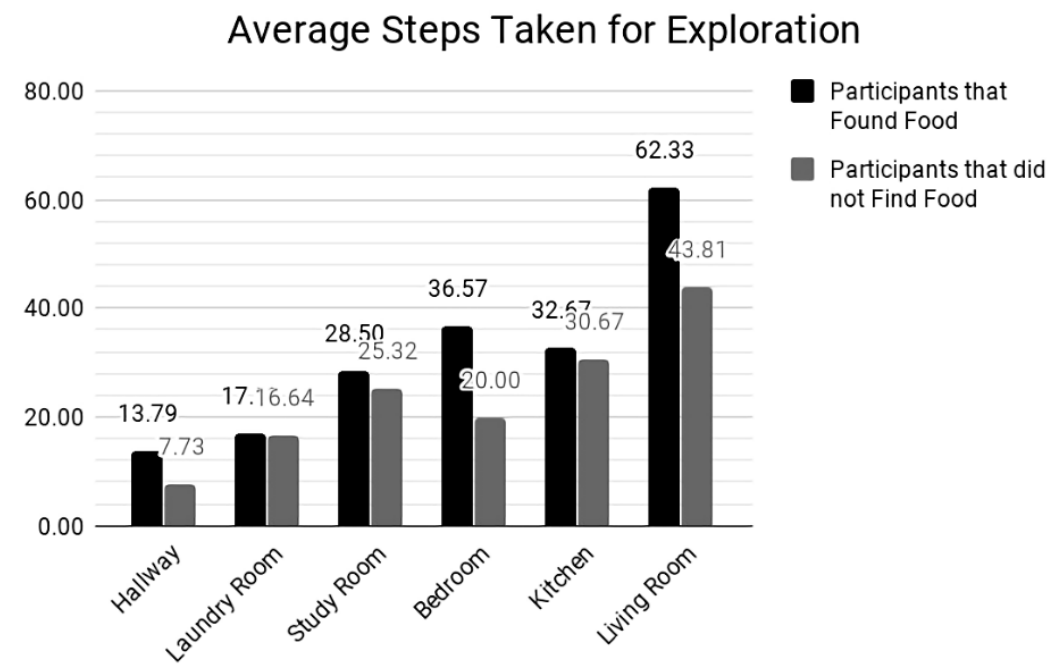

Figure 7. Average number of steps taken during exploration mode. 


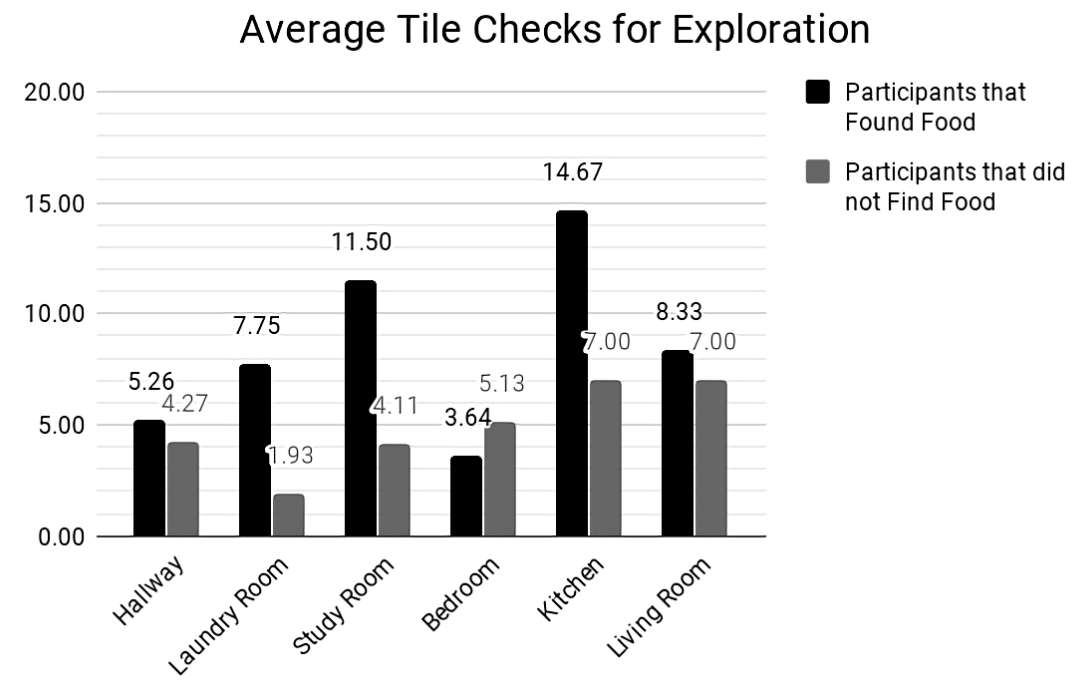

Figure 8. Average number of tile checks performed during exploration mode.

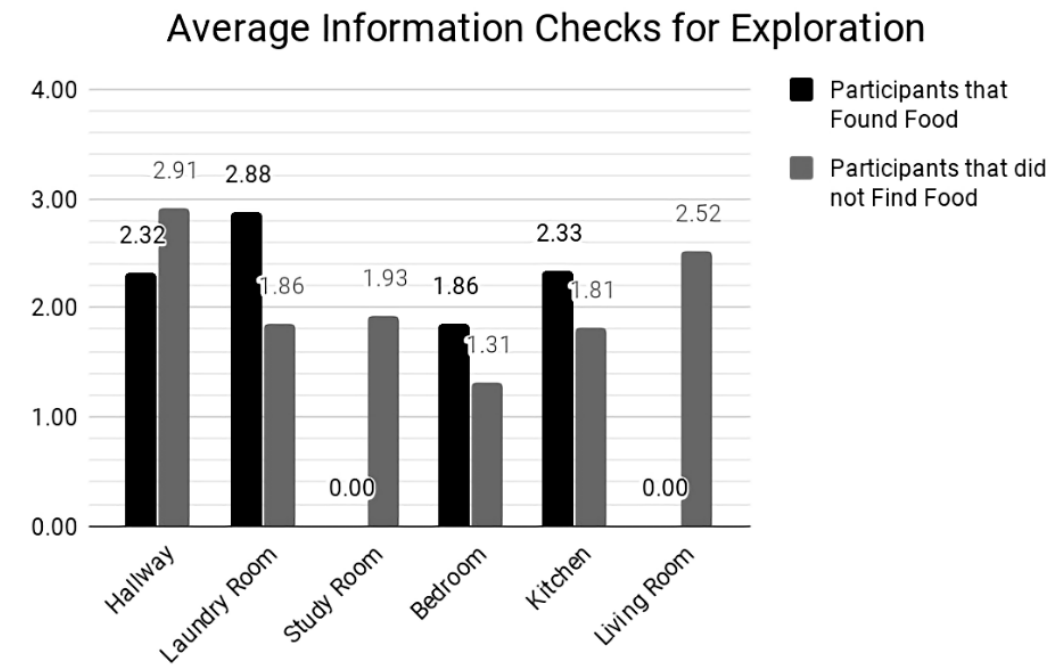

Figure 9. Average number of information checks performed during exploration mode.

Having taken a higher number of steps and performed a higher number of tile checks proved to be more helpful for locating the food during food finding mode, as it indicates that the participant explored a larger portion of the room or visited the same sections of the room more than once in their exploration. Figures 7 and 8 show that participants who found food in the food finding test consistently performed both actions more than those who did not pass the test across all rooms. The exception to this trend is the bedroom in Figure 8, where participants that managed to find the food had performed fewer tile checks on average (3.64) compared to participants who did not find food (5.13). Despite performing fewer tile checks during exploration mode for this room, the participants who found the food had taken significantly more steps on average (36.57) than their counterparts who did not find the food (20.00). This shows that, overall, the participants who found food did still explore the room more than the participants who did not find food.

Based on the results discussed, a participant who was a secondary school student (32.54\%) with low vision $(36.27 \%)$ and no learning difficulties $(33.34 \%)$ was more likely to find the food than a participant who was a primary school student $(29.63 \%)$ with no vision $(25.64 \%)$ and with learning difficulties $(26.19 \%)$. The success rate of food finding also dropped with the increase of virtual room's size as well. In larger rooms such as the kitchen and living room, there might not be sufficient time to succeed in food finding if they are not familiar with the room. 
Although the overall trend showing that participants without learning difficulties $(33.35 \%)$ performed better in comparison to participants who are with learning difficulties $(26.19 \%)$, there were significantly fewer participants in the learning difficulty group (7 participants) when compared to the group without learning difficulty (23 participants). Therefore, the results from the tests were not conclusive enough to support that having a learning difficulty would adversely affect one's spatial mapping skills.

\subsection{Wire Net Tests Results}

The wire net test involved the participant pointing out the location of the furniture they have discovered on a wire net frame. To measure how well the participants performed in this test, two scores were calculated: the item discovery score and the item accuracy score.

Item discovery score: The item discovery (\%) for a room referred to the average item discovery for all items in the room. Each item in the room was awarded a $0 \%$ if undiscovered by the participant and $100 \%$ if discovered by the participant. Therefore, if a participant found and listed three out of four items of the room, they received a $75 \%$ score for item discovery. However, if an extra item was found that does not exist in the room, a penalty was incurred. The amount deducted was dependent on the number of items in the room, resulting in a $25 \%$ deduction for a room of four items if five items were listed by the participant during the wire net test. Having a high item discovery score means that the participant knows the furniture placed in the virtual room. This indicated that the participant had learned about the room and gathered spatial information about it through playing Hungry Cat.

Item accuracy score: When an item was discovered, only then was the item's accuracy score calculated. The item accuracy for the room referred to the average item accuracy of all the items in that room. The item's accuracy was calculated based on two variables: placement of the item and furniture size of the item.

When an item was placed in the exact position, it yielded 100\% for placement accuracy. This score was reduced by $20 \%$ for every one tile the placement was off from the original location, thus being off by five tiles and above yielded a $0 \%$ for the placement score. The placement of the tile was based on the center of the object and a half tile difference in position was considered as zero tile difference as this difference was reflected in the difference in the furniture's item size. Having a high item accuracy score indicated that the participant not only knows the furniture placed in the room, but he/she also knows in detail the size and placement of them. This showed that a participant had created a detailed spatial mental map of the room from the spatial information gathered while exploring the room through playing Hungry Cat.

If the item size was correct, the item yielded $100 \%$ for size accuracy. The score was reduced by $20 \%$ for every tile in different sizes. By indicating a size with a difference of five tiles or more compared to the original item size, the participant received a $0 \%$ for the item size. The same condition applied whether the size stated by the participant was smaller or larger than the actual item.

The item accuracy was then calculated based on the average of both the item placement score and the item size score. Thus, if a player scored $100 \%$ in item placement but $50 \%$ in item size, they would get $(100 \%+50 \%) / 2=75 \%$ for the final item accuracy. Not discovering the item in the first place automatically yielded a $0 \%$ for item accuracy.

Table 3 indicates the average item discovery score and the average item accuracy score for all items in each room for all participants. It shows that exploration of the rooms while playing Hungry Cat did provide the participants with spatial information about each room during the exploration mode. The participants were able to name the majority of the furniture in the rooms they had explored, as seen by the discovered (\%) rows for each room.

The item discovery and item accuracy scores decreased as the rooms became more complex due to the same amount of time given for the exploration of different difficulty levels. Despite the decrease in scores as the game levels increased, it still showed that a spatial mental map of the rooms could be constructed through playing the game. Although not fully accurate, as seen from the average item 
accuracy $(\%)$, as proven by the high average for the item discovered (\%) for all rooms, participants were able to remember the furniture they have discovered in the virtual room as well as the general size and placement of them. The result shows that $64.29-92.22 \%$ of the items were discovered for each room. The most difficult virtual room had $31.33 \%$ average item accuracy score due to the size and number of furniture, while the easiest room had an average item accuracy score of $75.00 \%$.

Table 3. Average success rate of wire net test according to room items.

\begin{tabular}{|c|c|c|c|c|c|c|c|c|c|}
\hline Room & \multicolumn{9}{|c|}{ Game Level 1-Hallway } \\
\hline Furniture & Coat Hanger & Shoe Rack & $\mathrm{N} / \mathrm{A}$ & $\mathrm{N} / \mathrm{A}$ & $\mathrm{N} / \mathrm{A}$ & $\mathrm{N} / \mathrm{A}$ & $\mathrm{N} / \mathrm{A}$ & $\mathrm{N} / \mathrm{A}$ & Avg. \\
\hline Discovered $(\%)$ & 83.33 & 96.67 & 0.00 & 0.00 & 0.00 & 0.00 & 0.00 & 0.00 & 90.00 \\
\hline Average Item Accuracy (\%) & 70.33 & 79.67 & 0.00 & 0.00 & 0.00 & 0.00 & 0.00 & 0.00 & 75.00 \\
\hline Room & \multicolumn{9}{|c|}{ Game Level 2-Laundry Room } \\
\hline Furniture & $\begin{array}{l}\text { Laundry } \\
\text { Machine }\end{array}$ & Pails & Sink & $\mathrm{N} / \mathrm{A}$ & $\mathrm{N} / \mathrm{A}$ & $\mathrm{N} / \mathrm{A}$ & $\mathrm{N} / \mathrm{A}$ & $\mathrm{N} / \mathrm{A}$ & Avg. \\
\hline Discovered $(\%)$ & 100.00 & 86.67 & 90.00 & 0.00 & 0.00 & 0.00 & 0.00 & 0.00 & 92.22 \\
\hline Average Item Accuracy (\%) & 74.67 & 70.33 & 65.00 & 0.00 & 0.00 & 0.00 & 0.00 & 0.00 & 70.00 \\
\hline Room & \multicolumn{9}{|c|}{ Game Level 3-Study Room } \\
\hline Furniture & Book Rack 1 & Book Rack 2 & Chair & $\begin{array}{c}\text { Portable } \\
\text { AC }\end{array}$ & Table & $\mathrm{N} / \mathrm{A}$ & $\mathrm{N} / \mathrm{A}$ & $\mathrm{N} / \mathrm{A}$ & Avg. \\
\hline Discovered $(\%)$ & 93.33 & 56.67 & 70.00 & 86.67 & 90.00 & 0.00 & 0.00 & 0.00 & 79.33 \\
\hline Average Item Accuracy (\%) & 72.33 & 35.00 & 56.67 & 60.33 & 37.33 & 0.00 & 0.00 & 0.00 & 52.33 \\
\hline Room & \multicolumn{9}{|c|}{ Game Level 4-Bedroom } \\
\hline Furniture & Bed & Closet & Plant & $\begin{array}{l}\text { Side } \\
\text { Table }\end{array}$ & $\mathrm{N} / \mathrm{A}$ & $\mathrm{N} / \mathrm{A}$ & $\mathrm{N} / \mathrm{A}$ & $\mathrm{N} / \mathrm{A}$ & Avg. \\
\hline Discovered $(\%)$ & 93.33 & 80.00 & 70.00 & 53.33 & 0.00 & 0.00 & 0.00 & 0.00 & 74.17 \\
\hline Average Item Accuracy (\%) & 28.33 & 49.67 & 46.00 & 36.67 & 0.00 & 0.00 & 0.00 & 0.00 & 40.17 \\
\hline Room & \multicolumn{9}{|c|}{ Game Level 5-Kitchen } \\
\hline Furniture & Cabinet & Chair 1 & Chair 2 & Chair 3 & Oven & Sink & $\begin{array}{l}\text { Stove } \\
\text { Counter }\end{array}$ & Table & Avg. \\
\hline Discovered $(\%)$ & 73.33 & 83.33 & 43.33 & 23.33 & 53.33 & 66.67 & 93.33 & 93.33 & 66.25 \\
\hline Average Item Accuracy (\%) & 36.33 & 63.67 & 32.00 & 16.33 & 35.67 & 46.33 & 36.00 & 49.67 & 39.50 \\
\hline Room & \multicolumn{9}{|c|}{ Game Level 6-Living Room } \\
\hline Furniture & Book Rack & Plant 1 & Plant 2 & Shelf & $\begin{array}{l}\text { Side } \\
\text { Table }\end{array}$ & Sofa & Table & $\mathrm{N} / \mathrm{A}$ & Avg. \\
\hline Discovered $(\%)$ & 66.67 & 63.33 & 23.33 & 66.67 & 66.67 & 76.67 & 86.67 & 0.00 & 64.29 \\
\hline Average Item Accuracy (\%) & 35.00 & 34.33 & 15.67 & 35.67 & 37.33 & 46.33 & 15.00 & 0.00 & 31.33 \\
\hline
\end{tabular}

In Table 4, the average item accuracy (\%) score is used as the wire net test scores as the item accuracy score was only calculated when the item was discovered. According to the table, primary school participants $(53.82 \%)$ performed better on average compared to secondary school participants $(52.52 \%)$ for all rooms with the exception of the hallway. This difference in performance may be due to individuals' abilities and self-motivation of the groups in participating in the test.

Table 4. Average wire net test scores for various groups.

\begin{tabular}{|c|c|c|c|c|c|c|c|}
\hline & Hallway & $\begin{array}{l}\text { Laundry } \\
\text { Room }\end{array}$ & $\begin{array}{l}\text { Study } \\
\text { Room }\end{array}$ & Bedroom & Kitchen & $\begin{array}{l}\text { Living } \\
\text { Room }\end{array}$ & Average \\
\hline Primary School Participants & 73.89 & 71.11 & 54.22 & 42.22 & 46.39 & 35.08 & 53.82 \\
\hline Secondary School Participants & 89.47 & 69.52 & 50.57 & 39.29 & 36.55 & 29.73 & 52.52 \\
\hline No Vision Participants & 68.46 & 67.18 & 51.69 & 37.69 & 36.35 & 26.59 & 47.99 \\
\hline Low Vision Participants & 80.00 & 72.16 & 51.65 & 42.06 & 41.91 & 34.96 & 53.79 \\
\hline Participants with LD & 71.43 & 63.81 & 62.29 & 38.21 & 43.93 & 31.43 & 51.85 \\
\hline Participants with No LD & 76.09 & 71.88 & 48.43 & 40.76 & 38.15 & 31.30 & 51.10 \\
\hline Participants who Found Food & 75.53 & 72.08 & 59.00 & 42.50 & 51.25 & 45.24 & 57.60 \\
\hline Participants who did not Find Food & 74.09 & 67.62 & 51.14 & 38.13 & 38.19 & 29.79 & 49.83 \\
\hline All Participants & 75.00 & 70.00 & 51.67 & 40.17 & 39.50 & 31.33 & 51.28 \\
\hline
\end{tabular}

Additionally, participants with low vision (53.79\%) performed better overall when compared to participants with no vision (47.99\%) according to the consistently better performances for all rooms. This was expected as participants with low vision were able to arrange their spatial information in a map-like way while participants with no vision (who were born blind) most likely arranged their 
spatial information of a location in a route-like method [6], therefore they required more experience with an environment to build a detailed spatial map of a place.

Furthermore, participants with learning difficulties (51.85\%) and without learning difficulties $(51.10 \%)$ performed differently in different virtual rooms. There was no trend that the group without learning difficulties performed consistently better than the group with learning difficulties. Although having learning difficulties might result in being slower at obtaining and storing spatial information, the performance of spatial mapping to gather spatial information still varied from individual to individual. An example is the case of Participant 1 who scored $100 \%$ on item accuracy in wire net test for the first room. Another case of participant with learning difficulties is Participant 23 who scored only $25 \%$ in the same test. This gives an exception that spatial mapping skills are not always affected by the learning disability in a visually impaired.

Finally, participants who passed the food finding test (57.60\%) performed better in the wire net test than those who did not manage to find the food (49.83\%) for each room. It comes to no surprise that participants who passed the food finding test also performed better in the wire net test across all rooms as both tests required a good spatial mental map of the room to perform well.

Figure 10 shows that participants who had passed the food finding test had an overall higher average for item accuracy for the rooms than their peers who did not manage to find food in the test. This indicated that participants who found the food during the test had clearer spatial mental maps of the rooms, thus they were able to perform better in the wire net test.

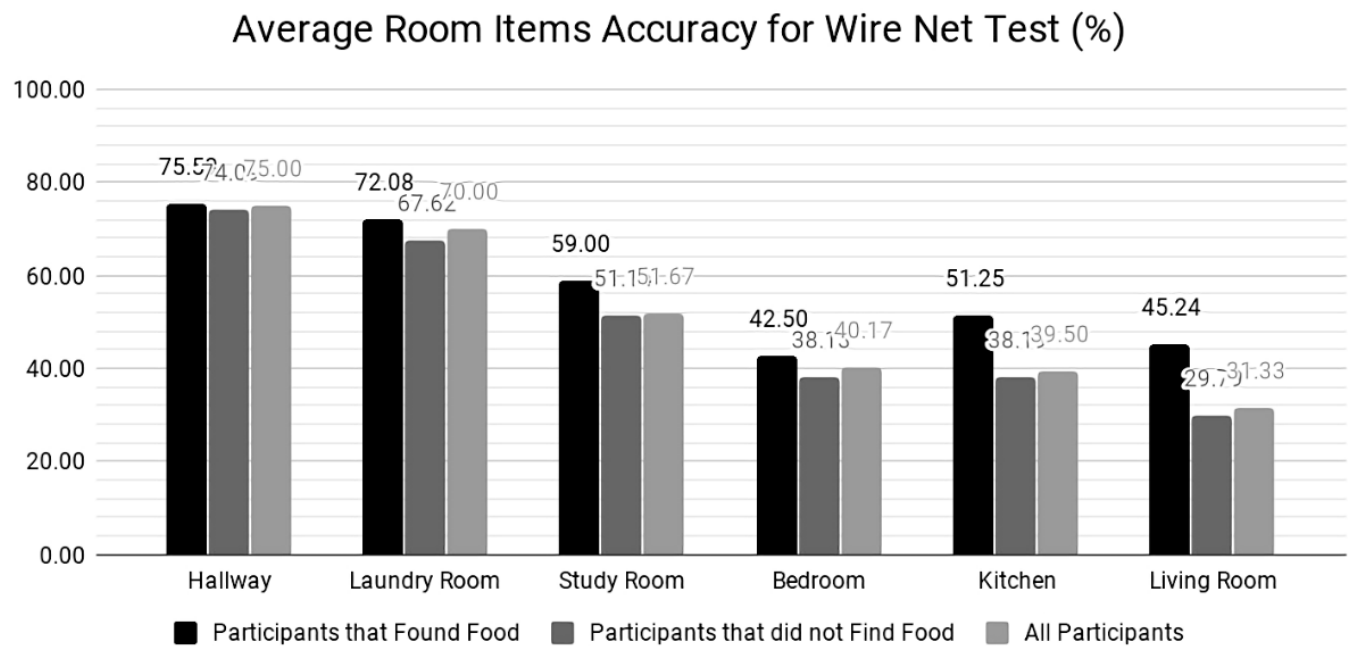

Figure 10. Average accuracy of room items size and placement by all participants.

\section{Discussions}

The Hungry Cat game is a learning tool that aims to convey spatial information of locations to children who have visual impairment by using the virtual rooms in the game. As observed from the positive results in the evaluation of Hungry Cat, the game was able to convey information about the room which the participants explored while playing the game. Even participants who were young (7-12 years old) or with learning difficulties were able to create the spatial mental map of the locations of furniture in the rooms. This can be seen from the results of the wire net test where primary school students as well as participants with learning difficulties also managed to discover items and provide their size and placement in the room. It was observed that the results for the food finding test and wire net test declined as the game progressed to more difficult level, i.e. larger rooms with more furniture items. This could due to the exploration time limit to $5 \mathrm{~min}$ being insufficient for exploring larger rooms with more items.

Participants who were successful for both the food finding test and the wire net test were those who explored the rooms more thoroughly during the exploration mode. It was evidenced by the 
higher number of steps taken and the higher number of tile checks which they performed, as shown in Figures 7 and 8. Participants who passed the food finding test also had higher item accuracy score for the wire net test.

Additionally, individual abilities for spatial information gathering and spatial mapping varied among the participants. For instance, one participant with learning difficulties performed poorly in the tests while another participant who had similar learning difficulties performed well in the same tests. Although there are general trends found for the average performance for the tests for each group of participants, there were cases where participants within the same group performed differently from the majority. For example, participants with low vision generally performed well, but a participant with low vision performed lower than average. This was due to their individual spatial mapping abilities, which were not assessed in detail in this study.

\section{Conclusions}

According to the positive results of the evaluation of the game prototype obtained from the 30 participants, the serious game Hungry Cat can convey spatial information to visually impaired children through spatial mapping while playing a game.

\section{Future Work}

For future work of the study, it is good to make the Hungry Cat fully blind friendly by making all screens navigable. A setting to adjust the speed in which the cat steps forward during game play may be added to allow more comfortable gameplay for beginners that may require a slower stepping speed as they get used to the control and for advanced players who wish to move around the game play room more quickly. More challenges should be added for the food finding mode by removing the step and direction details to the food's location. Instead, the food's location can be described in relation to an item in the room which will require the player to utilize their spatial mental map of the room, which they have gained through exploration mode to know where the food is quickly. Hungry Cat can be further improved with random food placements in food finding mode. This would allow the players to challenge the same room again without the problem of prior experience of locating the food affecting their results. Another future work would be to add more game levels. It is good to make Hungry Cat available on other platforms such as iOS. New levels may be added to map according to real rooms or building floors to perform real life spatial mapping evaluation with the visually impaired.

Author Contributions: Conceptualization, C.C. and B.T.L.; methodology, C.C. and B.T.L.; software, C.C.; validation, C.C., B.T.L. and Z.P.; formal analysis, C.C.; investigation, C.C.; resources, C.C. and B.T.L.; data curation, C.C.; writing-original draft preparation, C.C.; writing-review and editing, C.C., B.T.L. and Z.P.; visualization, C.C.; supervision, B.T.L. and Z.P.; project administration, C.C. and B.T.L.; and funding acquisition, B.T.L.

Funding: This research was funded by the Melbourne Sarawak Research Collaboration Scheme.

Conflicts of Interest: The authors declare no conflict of interest. The funders had no role in the design of the study; in the collection, analyses, or interpretation of data; in the writing of the manuscript, or in the decision to publish the results.

\section{References}

1. Tversky, B. Distortions in cognitive maps. Geoforum 1992, 23, 131-138. [CrossRef]

2. Loomis, J.M.; Klatzky, R.L.; Golledge, R.G. Navigating without Vision: Basic and Applied Research. Optom. Vis. Sci. 2001, 78, 282-289. [CrossRef] [PubMed]

3. Cobo, A.; Guerrón, N.E.; Martín, C.; del Pozo, F.; Serrano, J.J. Differences between blind people's cognitive maps after proximity and distant exploration of virtual environments. Comput. Hum. Behav. 2017, 77, 294-308. [CrossRef]

4. Lahav, O.; Gedalevitz, H.; Battersby, S.; Brown, D.; Evett, L.; Merritt, P. Virtual environment navigation with look-around mode to explore new real spaces by people who are blind. Disabil. Rehabil. 2017, 40, 1072-1084. [CrossRef] [PubMed] 
5. Cattaneo, Z.; Vecchi, T.; Cornoldi, C.; Mammarella, I.; Bonino, D.; Ricciardi, E.; Pietrini, P. Imagery and spatial processes in blindness and visual impairment. Neurosci. Biobehav. Rev. 2008, 32, 1346-1360. [CrossRef] [PubMed]

6. Noordzij, M.L.; Zuidhoek, S.; Postma, A. The influence of visual experience on the ability to form spatial mental models based on route and survey descriptions. Cognition 2006, 100, 321-342. [CrossRef] [PubMed]

7. De Felice, F.; Renna, F.; Attolico, G.; Distante, A. A haptic/acoustic application to allow blind the access to spatial information. In Proceedings of the Second Joint EuroHaptics Conference and Symposium on Haptic Interfaces for Virtual Environment and Teleoperator Systems, Tsukaba, Japan, 22-24 March 2007. [CrossRef]

8. Sánchez, J.; Sáenz, M. Metro navigation for the blind. Comput. Educ. 2010, 55, 970-981. [CrossRef]

9. Bardot, S.; Serrano, M.; Jouffrais, C. From tactile to virtual: Using a smartwatch to improve spatial map exploration for visually impaired users. In Proceedings of the 18th International Conference on Human-Computer Interaction with Mobile Devices and Services, Florence, Italy, 6-9 September 2016. [CrossRef]

10. Schneider, J.; Strothotte, T. Constructive exploration of spatial information by blind users. In Proceedings of the Fourth International ACM Conference on Assistive Technologies-Assets '00, Arlington, VA, USA, 13-15 November 2000. [CrossRef]

11. Sánchez, J. Development of Navigation Skills Through Audio Haptic Videogaming in Learners Who are Blind. Procedia Comput. Sci. 2012, 14, 102-110. [CrossRef]

12. Schloerb, D.W.; Lahav, O.; Desloge, J.G.; Srinivasan, M.A. BlindAid: Virtual environment system for self-reliant trip planning and orientation and mobility training. In Proceedings of the 2010 IEEE Haptics Symposium, Waltham, MA, USA, 25-26 March 2010. [CrossRef]

13. Lahav, O.; Schloerb, D.W.; Srinivasan, M.A. Rehabilitation program integrating virtual environment to improve orientation and mobility skills for people who are blind. Comput. Educ. 2015, 80, 1-4. [CrossRef] [PubMed]

14. Picinali, L.; Afonso, A.; Denis, M.; Katz, B.F.G. Exploration of architectural spaces by blind people using auditory virtual reality for the construction of spatial knowledge. Int. J. Hum. Comput. Stud. 2010, 72, 393-407. [CrossRef]

15. Seki, Y.; Sato, T. A Training System of Orientation and Mobility for Blind People Using Acoustic Virtual Reality. IEEE Trans. Neural Syst. Rehabil. Eng. 2011, 19, 95-104. [CrossRef] [PubMed]

16. Bowman, E.L.; Liu, L. Individuals with severely impaired vision can learn useful orientation and mobility skills in virtual streets and can use them to improve real street safety. PLoS ONE 2017, 12, e0176534. [CrossRef] [PubMed]

17. Geronazzo, M.; Bedin, A.; Brayda, L.; Campus, C.; Avanzini, F. Interactive spatial sonification for non-visual exploration of virtual maps. Int. J. Hum. Comput. Stud. 2016, 85, 4-15. [CrossRef]

18. Todd, C.A.; Naylor, K. A Haptic-Audio Simulator Indoor Navigation: To Assist Visually Impaired Environment Exploration. Int. J. Inf. Educ. Technol. 2016, 6, 178-186. [CrossRef]

19. Guerreiro, J.; Ahmetovic, D.; Kitani, K.M.; Asakawa, C. Virtual Navigation for Blind People. In Proceedings of the 19th International ACM SIGACCESS Conference on Computers and Accessibility-ASSETS '17, Baltimore, MD, USA, 20 October-1 November 2017. [CrossRef]

20. Lahav, O.; Mioduser, D. Construction of cognitive maps of unknown spaces using a multi-sensory virtual environment for people who are blind. Comput. Hum. Behav. 2008, 24, 1139-1155. [CrossRef]

21. Waller, D.; Hunt, E.; Knapp, D. The Transfer of Spatial Knowledge in Virtual Environment Training. Presence Teleoper. Virtual Environ. 1998, 7, 129-143. [CrossRef]

22. Karagiorgas, D.N.; Niemann, S. Gamification and Game-Based Learning. J. Educ. Technol. Syst. 2017, 45, 499-519. [CrossRef]

23. Treviño-Guzmán, N.; Pomales-García, C. How Can a Serious Game Impact Student Motivation and Learning? In Proceedings of the IIE Annual Conference, Montréal, QC, Canada, 31 May-3 June 2014.

24. Bul, K.C.M.; Doove, L.L.; Franken, I.H.A.; Van der Oord, S.; Kato, P.M. A serious game for children with Attention Deficit Hyperactivity Disorder: Who benefits the most? PLoS ONE 2018, 13, e0193681. [CrossRef] [PubMed]

25. Nasiri, N.; Shirmohammadi, S.; Rashed, A. A serious game for children with speech disorders and hearing problems. In Proceedings of the IEEE 5th International Conference on Serious Games and Applications for Health (SeGAH), Perth, Australia, 2-4 April 2017. [CrossRef] 
26. Connors, E.C.; Yazzolino, L.A.; Sánchez, J.; Merabet, L.B. Development of an Audio-based Virtual Gaming Environment to Assist with Navigation Skills in the Blind. J. Vis. Exp. 2013. [CrossRef] [PubMed]

27. Merabet, L.B.; Connors, E.C.; Halko, M.A.; Sánchez, J. Teaching the Blind to Find Their Way by Playing Video Games. PLoS ONE 2012, 7, e44958. [CrossRef] [PubMed]

28. Connors, E.C.; Chrastil, E.R.; Sánchez, J.; Merabet, L.B. Action video game play and transfer of navigation and spatial cognition skills in adolescents who are blind. Front. Hum. Neurosci. 2014, 8. [CrossRef] [PubMed]

(C) 2019 by the authors. Licensee MDPI, Basel, Switzerland. This article is an open access article distributed under the terms and conditions of the Creative Commons Attribution (CC BY) license (http://creativecommons.org/licenses/by/4.0/). 